\title{
VITAMIN E THERAPY IN RETINOPATHY OF PREMATURITY
}

\author{
D. P. R. MULLER \\ London
}

\begin{abstract}
SUMMARY
Vitamin $\mathbf{E}$ is a fat soluble antioxidant and as a result it is able to scavenge free radicals derived from oxygen. The premature infant and the retina are likely to be particularly vulnerable to the deleterious effects of these oxygen derived free radicals, and as a result prophylactic vitamin $E$ has been suggested for the management of retinopathy of prematurity (ROP). However, despite numerous trials, prophylactic supplementation with vitamin $\mathbf{E}$ remains controversial. This paper will critically review the use of vitamin $E$ in ROP and consider the risk/benefit relationship of such treatment in premature infants.
\end{abstract}

Retinopathy of prematurity (ROP), previously known as retrolental fibroplasia was first described by Terry in $1942^{1}$ and a beneficial effect of supplementation with vitamin $E$ was first suggested in $1949 .{ }^{2}$ Since then and up to the present time the role of prophylactic supplementation with vitamin $\mathrm{E}$ in ROP has been controversial. In this review the probable function of vitamin $\mathrm{E}$ in vivo will be discussed, and the theoretical reasons why vitamin $\mathrm{E}$ may be particularly important in the premature infant and in ROP considered. The evidence that prophylactic supplements of the vitamin may influence the incidence and severity of ROP will then be critically reviewed.

\section{VITAMIN E}

The biological activity of vitamin $\mathrm{E}$ is not limited to a single compound but is shared by a number of closely related derivatives of 2 methyl-2-(4', $8^{\prime}, 12^{\prime}$ trimethyltridecyl)-6-chromanol or tocol. These compounds belong to two series which differ in the degree of unsaturation of the phytyl side chain; those which are saturated are termed tocopherols and those with an unsaturated side chain tocotrienols. Within each group, there are four compounds (designated alpha-, beta-, gamma-, and delta-), which differ according to the number and position of the methyl groups on the chromanol ring. Of these, alphatocopherol has the greatest biological activity ${ }^{3}$ and

Correspondence to Institute of Child Health, 30 Guilford Street, London WC1 1EH accounts for approximately $90 \%$ of all the tocopherols present in human tissues. ${ }^{4}$ Supplements of vitamin E are generally given in the form of the acetate ester of alphatocopherol which is hydrolysed in vivo to give the active free alpha-tocopherol.

The biological activity of vitamin E results principally from its antioxidant properties. ${ }^{5}$ Antioxidants are essential to protect molecules and biological systems from oxidative damage by oxygen-derived free radicals. These are chemical species with an unpaired electron which as a result are highly reactive and able to react with many molecules in living cells, producing in most cases another free radical and thereby generating a chain reaction. Oxygenderived free radicals, such as the superoxide anion radical or hydroxyl radical, are produced as a result of many biological reactions, including oxidative phosphorylation, enzymatic reactions, inflammatory processes, detoxification of drugs via the cytochrome P450 system, and as the principal process by which neutrophils kill bacteria. ${ }^{6}$ If production of these highly reactive free radical species is allowed to proceed unchecked, they are able to oxidise a variety of biologically important molecules and cause membrane and cell damage. Antioxidant defences can be divided into two groups: firstly preventative antioxidants such as catalase and glutathione peroxidase which prevent the formation of free radical species, and secondly chainbreaking antioxidants such as superoxide dismutase, ascorbate, urate, and vitamin $E$ which trap oxygen-derived free radicals and halt the chain reaction.

The importance of vitamin $E$ lies in the fact that it is the only well recognised, lipid-soluble, chain-breaking antioxidant. ${ }^{5}$ It is able to trap radicals formed as a result of the oxidation of the unsaturated fatty acids of membrane phospholipids and thereby prevent lipid peroxidation. Vitamin $E$ is likely, therefore, to be important for maintaining the integrity and stability of biological membranes.

\section{THE EYE}

There are a number of features which make the retina particularly susceptible to autoxidation by oxygen- 
derived free radicals and, therefore, particularly vulnerable to a deficiency of antioxidants such as vitamin E. ${ }^{7}$ The retina is served with a plentiful supply of oxygen, has an abundant supply of mitochondria, and an unusually high rate of oxidative metabolism. Thus, an increased leak of oxygen-derived free radicals may occur and result in increased lipid peroxidation. The membranes of the rod outer segments are particularly vulnerable to peroxidation as more than $65 \%$ of the membrane fatty acids are polyunsaturated, which is the highest proportion found in any vertebrate tissue examined to date. The retina is also frequently exposed to intense light which can be phototoxic. Light of wavelength greater than $400 \mathrm{~nm}$ cannot of itself break covalent bonds but damage may result from a thermal mechanism, or through a photosensitising process which may also produce oxygen-derived free radicals.

There are at least three conditions of the eye where a deficiency of vitamin $\mathrm{E}$ has either been implicated and/or treatment with vitamin $E$ has been suggested. Firstly the well documented retinopathy associated with a severe and chronic deficiency of vitamin $\mathrm{E}$ has been described both in $\operatorname{man}^{8}$ and experimental animals. ${ }^{9}$ Secondly, treatment with antioxidants including vitamin $E$ is reported to be effective in limiting cataract formation ${ }^{10}$ and thirdly vitamin $\mathrm{E}$ therapy has been suggested for the management of ROP.

\section{THE NEWBORN}

The newborn and particularly the premature infant is theoretically at risk of damage from oxygen-derived free radicals because of both exposure to increased concentrations of oxygen derived free radicals and also reduced antioxidant defences. Thus at birth an infant abruptly enters a relatively hyperoxic extrauterine environment with the alveoli of the lung being exposed to an oxygen tension approximately five times greater than that during intrauterine development. The situation is further exacerbated in many small premature infants, where as part of the management of the respiratory distress syndrome they are exposed to increased concentrations (up to $100 \%$ ) of oxygen. Premature infants are also frequently exposed to high intensity illumination. In addition many studies have documented reduced serum concentrations of vitamin $E$ in the newborn. ${ }^{11-13}$ Initially it was thought that this resulted from impaired permeability of the placenta to alpha-tocopherol but it is now thought to be a function of a reduced transport capacity in the blood of the neonate. ${ }^{14}$ In the normal breast fed newborn, serum concentrations of vitamin E typically increase to within the normal adult reference range within two to three weeks, whereas it takes much longer to achieve these concentrations in the premature infant. As discussed above the net result of these factors is likely to be increased lipid peroxidation of membrane lipids. Among the products of in vivo lipid peroxidation are the volatile hydrocarbons, ethane and pentane which are eliminated in expired air. ${ }^{15}$ It has been reported that the excretion of these hydrocarbons is increased approximately tenfold in infants (mean age of 10 days) compared with adults ${ }^{16}$ confirming that there is indeed an increased rate of lipid peroxidation in the newborn.
As a consequence of these observations, vitamin $E$ therapy has been suggested for a number of conditions of the newborn where oxygen derived free radicals have been implicated e.g. bronchopulmonary dysplasia and intraventricular haemorrhage in addition to ROP. There is, however, no evidence that vitamin $E$ reduces the incidence of bronchopulmonary dysplasia, ${ }^{17}$ whereas the situation appears to be more encouraging in intraventricular haemorrhage. ${ }^{18-21}$

Observations on the ultrastructure of the developing retina have provided an explanation for the development of $\mathrm{ROP}$ and a possible role for vitamin $\mathrm{E} .^{22}$ The immature retina is supported by choroidal vessels. which appear early and retinal vessels which develop later. Development of the retinal vessels is dependent on the migration of spindle cells from the optic disc to the periphery which initially takes place in utero in a comparatively hypoxic environment. At birth oxygen from a relatively hyperoxic environment is able to diffuse freely across the retina because the immature choroidal vessels are unable to constrict. It is suggested that this results in free radical mediated damage to the spindle cells which prevents the normal formation of inner retinal vessels and causes abnormal vessel proliferation at the vascular/avascular boundary. The retina may then be invaded by a contractile sheet of myofibroblasts developing from this boundary region which may cause traction leading to retinal detachment. This sequence of events can progress relentlessly or regress spontaneously. It is suggested that the administration of vitamin $\mathrm{E}$ increases antioxidant activity and thus provides protection against this free radical mediated process.

The history of ROP and the controversy regarding vitamin $E$ therapy in this condition will now be considered.

\section{HISTORY OF RETINOPATHY OF PREMATURITY}

As mentioned previously, the original description of ROP was made in 1942.' In the 1950s the incidence of ROP increased and during this decade a number of investigations, including a collaborative study, ${ }^{23}$ indicated that the excessive use of oxygen was a major factor in the aetiology of the condition. It did not, however, explain many instances of ROP in low birth weight infants in whom no oxygen was administered, or the occurrence of the condition in only one eye. ${ }^{24}$ Because of the link between excessive use of oxygen and ROP, oxygen therapy was curtailed and this led to a dramatic decrease in the incidence of ROP in the 1960s. This was, however, associated with an increased mortality and morbidity particularly in infants with respiratory distress syndrome. It has been estimated that for each case of blindness prevented, approximately 16 babies died as a result of inadequate oxygenation. ${ }^{24}$ In the 1970s the use of oxygen in nurseries increased and this resulted in not only an increased survival of premature babies but also in a 'second epidemic of ROP'. The 1980s can be considered to be the decade when attempts at prevention have been made, and this has 
included numerous clinical trials of prophylactic supplements of vitamin $\mathrm{E}$.

\section{VITAMIN E AND RETINOPATHY OF PREMATURITY}

The first non-randomised trial of vitamin $\mathrm{E}$ in ROP was carried out in $1949^{2}$ which suggested that the vitamin might have a beneficial effect. Since then numerous trials of vitamin E supplementation have been carried out with conflicting results. Some reported no significant effect of vitamin $\mathrm{E}^{25-28}$ others a significant decrease in severity but not in incidence, ${ }^{29-33}$ whereas others reported a significant decrease in both incidence and severity of ROP. ${ }^{34,35}$ These differences in results are not altogether surprising when one considers the relatively small numbers of patients in many of the studies, the problems associated with low incidence events and the number of variables involved. The variables will include patient selection; dosage of vitamin $\mathrm{E}$ in controls (none or small doses); methods of administration of vitamin $\mathrm{E}$ (oral, intramuscular or intravenous); the dose, scheduling and duration of vitamin $\mathrm{E}$ treatment; the plasma vitamin E concentrations achieved and methods of statistical analysis.

These problems were addressed by Law et al. ${ }^{36}$ who analysed and combined seven randomised trials of vitamin E supplementation in ROP. For each trial the relative risk of developing ROP (i.e. the ratio of the proportion of treated infants who were affected to the proportion of the controls who were affected) and the $95 \%$ confidence intervals were calculated. A relative risk of 1.0 means that there is no reduction of ROP, and a relative risk of 0.8 that there is a $20 \%$ reduction. The relative risk estimated from the individual trials were then combined using standard statistical techniques ${ }^{37}$ to give a summary estimate. This was done for all infants with ROP and also for those with severe (>grade 3) ROP. The results summarised in the Table show that there was no statistically significant reduction in risk of ROP following vitamin $E$ treatment for either all infants with ROP or those with severe ROP. The results were therefore 'consistent with no effect at all'. On the other hand if vitamin $\mathrm{E}$ was effective, the relative risk for all infants was 0.95 and, therefore, no more than $5 \%$ of all premature infants would benefit from vitamin $\mathrm{E}$ supplementation.

A randomised trial in a total of 755 infants was recently reported by Johnson et al..$^{38}$ after Law et al. ${ }^{36}$ had completed their analysis. They reported a significant decrease in the incidence of ROP in the treated group, and although they found no significant decrease of severe ROP, they stated that the progression from moderate to severe ROP was less frequent following vitamin $\mathrm{E}$ treatment.

Despite the inconclusive nature of these studies, supplementation with prophylactic vitamin $\mathrm{E}$ might be acceptable if no hazard was involved. Thus both the incidence of ROP and the risk/benefit relationship of giving prophylactic vitamin $\mathrm{E}$ must be considered.

\section{INCIDENCE OF SEVERE ROP}

In 1982 Phelps estimated that in the United States, 22,000 infants of $<1,500 \mathrm{~g}$ would survive and of these 2,000 $(9.5 \%)$ would have severe ROP with cicatricial sequelae and $500(2.3 \%)$ would be blind. ${ }^{39}$ The incidence of ROP and blindness appears to increase with decreasing birthweight, so that reports from various countries have given an incidence of blindness in infants of $<1.0 \mathrm{~kg}$ of between $4.5-8.0 \%{ }^{40}$

In the only recent prospective epidemiological survey in the United Kingdom, $\mathrm{Ng}$ et al. ${ }^{41}$ reported that ROP developed in $49 \%$ of 505 infants weighing $1.7 \mathrm{~kg}$ or less born during 1985-1987. Of these 4.5\% developed severe (stage 3 and 4 ) and $1 \%$ cicatricial ROP. There were no cases of blindness.

If prophylactic vitamin $\mathrm{E}$ is given to all premature infants, a very large percentage of infants (approximately $90 \%$ in the United States and more than $90 \%$ in the United Kingdom) would be given the vitamin who would not develop the severe form of the condition. This is acceptable if such supplementation was completely safe or that the benefits strongly outweigh the risks. Reports have, however, appeared which suggest that there may be risks associated with the prophylactic administration of vitamin $E$ to the premature infant.

\section{POSSIBLE RISKS ASSOCIATED WITH VITAMIN E ADMINISTRATION}

There have been reports which suggest that there is an increased incidence of necrotising enterocolitis in infants given vitamin E supplements. Finer et al., ${ }^{35}$ in a retrospective study of patients given the vitamin to reduce the severity of ROP, found a significant increase in the incidence of necrotising enterocolitis in infants weighing less than $1,500 \mathrm{~g}$ given oral vitamin $\mathrm{E}$. They suggested that this resulted from the hyperosmolarity of the oral preparation used. Johnson et al., ${ }^{42}$ however, used an intramuscular preparation of vitamin $\mathrm{E}$ in a prospective study and also found a significantly increased incidence of necrotising enterocolitis. They also reported a significantly increased incidence of sepsis in the treated group. In this latter study, serum vitamin $\mathrm{E}$ tended to reach supranormal concentrations (mean of $5 \mathrm{mg} / 100 \mathrm{ml}$ ) compared with a normal adult concentration of approximately $0.8 \mathrm{mg} / 100 \mathrm{ml}$. The authors sugested that these high concentrations resulted in excess antioxidant capacity which impaired the normal oxygen-dependent antimicrobial defence mechanisms and resulted in an increased susceptibility to infection.

In 1983 an intravenous vitamin E preparation, E-Ferol, was marketed and used pharmacologically for the prevention of ROP in the United States. It was, however, recalled

Table. Summary analysis of seven randomised controlled trials of vitamin E supplementation ${ }^{36}$

\begin{tabular}{lccc}
\hline & $\begin{array}{c}\text { Relative } \\
\text { risk }\end{array}$ & $\begin{array}{c}95 \% \text { confidence } \\
\text { intervals }\end{array}$ & \\
\hline $\begin{array}{l}\text { All ROP } \\
\begin{array}{l}\text { Severe ROP } \\
(>\text { grade 3) }\end{array}\end{array}$ & 0.95 & $0.84-1.07$ & NS \\
\hline
\end{tabular}

NS—not significant. 
in the following year following the deaths of 38 infants who had received this preparation. ${ }^{43}$ The syndrome associated with E-Ferol comprised pulmonary deterioration, thrombocytopenia, liver failure, ascites and renal failure. ${ }^{44}$ Since discontinuation of the preparation the condition disappeared. The mechanism underlying this syndrome appears to be related to the carrier (polysorbate 80 ) used in the preparation rather than to vitamin $\mathrm{E}$ itself. ${ }^{45}$

\section{CONCLUSIONS}

Despite many randomised and controlled trials the efficacy of prophylactic supplements of vitamin $E$ in either reducing the incidence or the severity of ROP remains controversial. In view of the reports of an increased incidence of necrotising enterocolitis and sepsis associated with vitamin E supplementation, the risk/benefit relationship of prophylactic vitamin $E$ administration remains to be clarified. We must, therefore, agree with the recommendation of an American Committee on Fetus and Newborn ${ }^{46}$ which concluded:

'At this time, however, the Committee regards prophylactic use of pharmacological vitamin $\mathrm{E}$ as experimental and cannot recommend that high doses of vitamin $\mathrm{E}$ be given routinely to infants weighing less than $1,500 \mathrm{~g}$, even if such use is limited to infants who require supplemental oxygen'

and also with the statement of Law et $\mathrm{al}^{36}$ that

'Future priority must be to exclude hazard rather than confirm benefit'.

\section{REFERENCES}

1. Terry TL: Extreme prematurity and fibroblastic overgrowth of persistent vascular sheath behind each crystalline lens. I. Preliminary report. Am J Ophthalmol 1942, 25: 203-4.

2. Owens WC and Owens EU: Retrolental fibroplasia in premature infants. II. Studies on the prophylaxis of the disease: the use of alpha-tocopheryl acetate. Am J Ophthalmol 1949 , 32: 1631-7.

3. Century B and Horwitt MK: Biological availability of various forms of vitamin $E$ with respect to different indices of deficiency. Fed Proc 1965, 24: 906-11.

4. Bieri JG and Prival EL: Serum vitamin E determined by thin layer chromatography. Proc Soc Exp Bio Med 1965, 120: 554-7.

5. Burton GW, Joyce A, Ingold KU: Is vitamin E the only lipid soluble chain-breaking antioxidant in human blood plasma and erythrocyte membranes? Arch Biophys 1983, 221: 281-90.

6. Halliwell B and Gutteridge JMC: Free radicals in biology and medicine. Oxford University Press, Oxford 1985.

7. Handelman GJ and Dratz. EA: The role of antioxidants in the retina and retinal pigment epithelium and the nature of prooxidant-induced damage. Adv Free Radical Bio Med 1986, 2: $1-89$.

8. Runge P, Muller DPR, McAllister J, Calver D, Lloyd JK, Taylor D: Oral vitamin E supplements can prevent the retinopathy of abetalipoproteinaemia. Br J Ophthalmol 1986, 70: $166-73$.

9. Robison WG, Kuwabara T, Bieri JG: Deficiencies of vitamins $E$ and $A$ in the rat. Retinal damage and lipofuscin accumulation. Invest Ophthalmol Vis Sci 1980, 19: 1030-7.

10. Ross WM, Creighton MO, Inch WR, Trevithick JR: Radiation cataract formation diminished by vitamin $\mathrm{E}$ in rat lenses in vitro. Exp Eye Res 1983, 36: 645-53.
11. Straumfjord JB and Quaife ML: Vitamin E levels in maternal and fetal blood plasma. Proc Soc Exp Biol Med 1946, 61: 369-71.

12. Wright SW, Filer LJ, Mason KE: Vitamin E blood levels in premature and full term infants. Pediatric's 1951, 7:386-93.

13. Leonard PJ, Doyle E, Hartington N: Levels of vitamin E in the plasma of newborn infants and of the mothers. Am J Clin Nutr 1972, 25: 480-4.

14. Hage P, Ek J, Kran S: Plasma tocopherol levels and vitamin E/ $\beta$-lipoprotein relationships during pregnancy and in cord blood. Am J Clin Nutr 1982, 36: 1200-4.

15. Riely CA, Cohen G, Liverman M: Ethane evolution: a new index of lipid peroxidation. Science 1974, 183: 208-10.

16. Wispe JR, Bell EF, Roberts RJ: Assessment of lipid peroxidation in newborn infants and rabbits by measurements of expired ethane and pentane: influence of parenteral lipid infusion. Ped Res 1985, 19: 374-9.

17. Arande JV, Chemtob S. Laudignon N, Sasynvic BI: Furosemide and vitamin $\mathrm{E}$ : two problem drugs in neonatology. Pediat Clin N Am 1986, 33: 583-602.

18. Chiswick ML, Johnson M, Woodall C, Gowland M, Davies J, Toner N, Sims DG: Protective effect of vitamin E (DLalpha-tocopherol) against intraventricular haemorrhage in premature babies. Br Med J 1983, 287, 81-4.

19. Speer ME, Blifeld C, Rudolph AJ, Chadda P, Holbein MEG, Hittner HM: Intraventricular haemorrhage and vita$\min E$ in the very-low-birth-weight infant: evidence for efficacy of early intramuscular vitamin $\mathrm{E}$ administration. Pediatrics 1984, 74: 1107-12.

20. Sinha S, Davies J, Toner N, Bogle S, Chiswick M: Vitamin E supplementation reduces frequency of periventricular haemorrhage in very preterm babies. Lancet 1987, 1: 466-71.

21. Fish WH, Cohen M, Franzek D, Williams JM, Lemons JA: Effect of intramuscular vitamin E on mortality and intracranial haemorrhage in neonates of $1,000 \mathrm{gms}$ or less. Pediatrics 1990, 85: 578-84.

22. Kretzer FL and Hittner HM: Retinopathy of prematurity: clinical implications of retinal development. Arch Dis Childh 1988, 63: 1151-67.

23. Kinsey VE: Retrolental fibroplasia: cooperative study of retrolental fibroplasia and the use of oxygen. Arch Ophthalmol 1956, 56: 481-543.

24. Lucey JF and Dangman D: A reexamination of the role of oxygen in retrolental fibroplasia. Pediatrics 1984, 73: $82-97$.

25. Watts JL, Milner RA, McCormick AQ: Failure of vitamin E to prevent RLF. Clin Invest Med 1985, 8: A 176.

26. Pukin JE, Simon RM. Ehrenkranz RA: Influence on retrolental fibroplasia of intramuscular vitamin $\mathrm{E}$ administration during respiratory distress syndrome. Ophthalmol 1982,89, 96-102.

27. Phelps DL, Rosenbaum AL, Isenberg SJ, Leade RD, Dorey FJ: Tocopherol efficacy and safety for preventing retinopathy of prematurity: a randomised, controlled, doublemasked trial. Pediatrics 1987, 79: 489-500.

28. Bremer DL and Rogers GL: The efficacy of vitamin E in retinopathy of prematurity. J Ped Ophthalmol Strab 1986, 23: 132-6.

29. Schaffer DB, Johnson L, Quinn GE, Weston M, Bowen FW: Vitamin E and retinopathy of prematurity. Ophthalmol 1985, 92: 1005-11.

30. Finer NN, Schindler RF, Grant G, Hill GB, Peters KL: Effect of intramuscular vitamin E on frequency and severity of retrolental fibroplasia. Lancet 1982, 1: 1087-91.

31. Hittner HM, Godio LB, Rudolph AJ, Adams JM, Garcia Prats JA, Friedman Z. Kautz JA, Monaco WA: Retrolental fibroplasia: efficacy of vitamin $\mathrm{E}$ in a double-blind clinical study of preterm infants. N Engl.J Med 1981, 305: 1365-71.

32. Hittner HM, Speer ME, Rudolph AJ, Blifeld C, Chadda P, 
Holbein MEB, Godio LB, Kretzer FL: Retrolental fibroplasia and vitamin $\mathrm{E}$ in the preterm infant - comparison of oral versus intramuscular: oral administration. Pediatrics 1984, 73: 238-49.

33. Hittner HM, Godio LB, Speer ME, Rudolph AJ, Taylor MM, Blifeld C, Kretzer FL: Retrolental fibroplasia: further clinical evidence and ultrastructural support for efficacy of vitamin E in the preterm infant. Pediatrics 1983, 71: 423-32.

34. Johnson L, Schaffer D, Boggs TR: The premature infant, vitamin E deficiency and retrolental fibroplasia. Am J Clin Nutr 1974, 27: 1158-73.

35. Finer NN, Peters KL, Hayek Z, Merel CL: Vitamin E and necrotizing enterocolitis. Pediatrics 1984, 73: 387-93.

36. Law MR, Wijewardene $\mathrm{K}$, Wald $\mathrm{NJ}$ : Is routine vitamin $\mathrm{E}$ administration justified in very low birth weight infants? Devel Med Child Neurol 1990, 32: 442-50.

37. Armitage $P$ and Berry B: Statistical methods in medical research. Oxford, Blackwell 1987.

38. Johnson L, Quinn GE, Abbasi S, Otis C, Goldstein D, Sacks L, Porat R, Fong E, Delivoria-Papadopoulos M, Peckham G, Schaffer DB, Bowen FW: Effect of sustained pharmacologic vitamin E levels on incidence and severity of ret- inopathy of prematurity: a controlled clinical trial. $J$ Peds 1989, 114: 827-38.

39. Phelps DL: Vitamin E and retrolental fibroplasia in 1982. Pediatrics 1982, 70: 420-5.

40. Anon: Retinopathy of prematurity. Lancet 1991, 337: 83-4.

41. NG YK, Fielder AR, Shaw DE, Levene MI: Epidemiology of retinopathy of prematurity. Lancet 1988, II: 1234-8.

42. Johnson L, Bowen FW, Abbasi S, Herrmann N, Weston M, Sacks L, Porat R, Stahl G, Peckham G, Delivoria-Papadopoulos M, Quinn G, Schaffer D: Relationship of prolonged pharmacological serum levels of vitamin $E$ to incidence of sepsis and necrotizing enterocolitis in infants with birth weight 1,500 grams or less. Pediatrics 1985,75 : 619-38.

43. Phelps DL: E-Ferol: what happened and what now? Pediatrics 1984, 74: 1114-6.

44. Lorch V, Murphy D, Hoersten LR, Harris E, Fitzgerald J, Sinha SN: Unusual syndrome among premature infants: association with a new intravenous vitamin E product. Pediatrics 1985, 75: 598-602.

45. Alade SL, Brown RE, Paquet A: Polysorbate 80 and E-Ferol toxicity. Pediatrics 1986, 77: 593-7.

46. Committee on Fetus and Newborn: Vitamin E and the prevention of retinopathy of prematurity. Pediatrics 1985 , 76: $315-6$. 